\section{Treatment of Rectal Cancer with Trans-Anal Mesorectal Excision: A Mini-Review of the Literature}

\section{Abstract}

Background: The aim of this mini-review is to summarize the body of literature based on studies on the perioperative and oncological outcomes of transanal total mesorectal excision (TaTME) for the treatment of rectal cancer.

Methods: A literature search of PubMED database was performed using subject headings and keywords related to rectal adenocarcinoma and transanal mesorectal excision.

Results: Five case series were identified, reporting on a total of 378 patients with mean/median age ranging from 56.5 to 67.6 years and body mass index ranging from 25.2 to $27.5 \mathrm{~kg} / \mathrm{m}^{2}$. The mean/median operative time was 166 to 270 minutes. Conversion rate to open approach ranged from $0 \%$ to $7.3 \%$ whereas postoperative complication rate ranged from $26 \%$ to $39 \%$. The length of stay ranged from 4.5 to 10 days. The completeness of circumferential resection margin (CRM) was reported to be between $72 \%$ to $97.1 \%$. CRM positivity ranged from $2.5 \%$ to 6.4\%. The distal resection margin (DRM) ranged from $10 \mathrm{~mm}$ to $37.1 \mathrm{~mm}$ and DRM positivity ranged from $0 \%$ to $2 \%$. The mean/median lymph node harvested ranged from 12 to 20. Short-term oncological outcome (median follow-up period of 15.1 to 29 months) was reported with local recurrence rate from $1.9 \%$ to $4 \%$ and distal recurrence rate of $3.9 \%$ to $14.5 \%$.

Conclusions: TaTME appears to be a safe technique for treatment of rectal cancer although the current evidence is limited by the heterogeneity of the quality of available studies. Randomized control trials would be necessary to assess the longterm safety and oncological outcomes of TaTME as compared to conventional rectal surgery techniques.

Keywords: Transanal total mesorectal excision; Transanal surgery; Minimally invasive surgery; Rectal cancer; Laparoscopic rectal surgery; Systematic review

\section{Eric Hyun ${ }^{1,2}$, Jon Cottreau ${ }^{1}$, Pejman Sadeghi $i^{1,2}$ and Michele Molinari ${ }^{1,2}$}

\section{Dalhousie University Medical School, Halifax Nova Scotia, Canada \\ 2 QEII Health Sciences Centre, Halifax Nova Scotia, Canada}

Corresponding author: Michele Molinari

”michele.molinari@nshealth.ca

1276 South Park Street, Office 6-302 Victoria General Hospital, Halifax Nova Scotia, Canada.

Tel: +19024737625

Citation: Hyun E, Cottreau J, Sadeghi P. et al. Treatment of Rectal Cancer with TransAnal Mesorectal Excision: A Mini-Review of the Literature. Colorec Cancer 2016, 2:3.

\section{Introduction}

Total mesorectal excision (TME) during open abdominal surgery has become the gold standard treatment for middle and lower rectal cancers [1]. First described by Heald et al. [1], in 1982, TME involves en bloc resection of rectal tumor and mesorectum [1,2]. TME decreases locoregional recurrence rates and increases overall survival after rectal cancer surgery [3]. Recent improvements in technology have had significant effects on how surgeons perform TME with an increasing interest in minimally invasive approaches. Laparoscopic TME (LapTME) has been shown by many randomized control trials (including COLOR II, COREAN, and CLASICC) to offer comparable clinical outcomes in terms of complications and oncological outcomes as compared to open TME [4-7]. Other studies have shown LapTME to be associated with less blood loss, shorter hospital stay, earlier return of bowel function, and fewer wound infections $[5,8,9]$.

LapTME may still be challenging in patients with unfavorable traits including low rectal tumors, narrow pelvic anatomy, male sex or high body mass index (BMI). Difficult visualization of the pelvic anatomy along with the limitation of rigid laparoscopic 
instruments may affect the quality of resection margins and increase the risks of neurovascular injuries during surgery. Two randomized trials (AlaCaRT and ACOSOG Z6051) demonstrated that laparoscopic rectal surgery did not meet non-inferiority for oncological resection quality when compared to the classic open approach $[10,11]$. However, conversion rate from laparoscopic to open TME surgery was as high as 34\% [12-14].

In an effort to address these limitations associated with LapTME, a novel concept of "down to up" transanal TME (TaTME) has been proposed by several authors Sylla, De lacy, Heald [1517]. The concept of TaTME has become a reality because of the improvements of transanal abdominal proctosigmoidectomy (TATA), transanal endoscopic microsurgery (TEMS), transanal minimally invasive surgery (TAMIS), and natural orifice transluminal endoscopic surgery (NOTES) [18-20]. TATA was introduced in 1984 by Marks et al. [19]. By starting transanally and establishing a safe distal resection margin (DRM) as a first step, Marks et al. were able to perform more sphincter preserving surgeries and decrease the need for permanent colostomies [19]. TEMS approach was introduced in 1984 by Buess et al. $[18,21]$, and involves excision of rectal lesions using an operating proctoscope, endoluminal insufflations, and specialized endoscopic instruments used within pneumorectum [18,21]. TEMS allows access to the middle and the upper rectum (up to $20 \mathrm{~cm}$ from the anal verge). A full thickness rectal wall excision can be made to remove the rectal tumor and the defect can be left open or sutured closed. TAMIS is a similar technique to TEMS but it involves a use of low-cost single incision laparoscopic port and standard laparoscopic instruments [22,23]. NOTES allows surgical procedure through natural orifices via transgastric, transvaginal or transrectal approach. In 2007, Whiteford et al. [24] described the feasibility of performing rectosigmoidectomy via transanal route using TEMS platform on a human cadaver. Since then, numerous animal and human cadaver studies have illustrated safety and feasibility of TaTME [20,25-28]. In 2010, the first clinical case report of TaTME using TEMS with laparoscopic assistance was published by Sylla et al. [20]. Furthermore, TaTME approach has been applied outside the setting of rectal cancer including completion proctectomy in patients with inflammatory bowel disease and reversal of Hartmann's procedure $[29,30]$.

The aim of this mini-review is to summarize the body of literature based on studies looking at the safety and feasibility of TaTME for the treatment of rectal cancer. TaTME is a technique that requires expertise in both laparoscopic rectal surgery and TEMS/TAMIS techniques. Case reports and small case series may reflect outcomes during the early learning phase and may not truly reflect the whole spectrum of complication rate and oncological outcomes following TaTME surgery. In order to mitigate this, our review study focused only on larger case series that involved 50 or more participants. The perioperative outcomes, histopathological results, and short-term oncological outcomes will be presented. Lastly, the key potential benefits and limitations of TaTME technique will be discussed.

\section{Surgical techniques highlights}

The procedure is performed using two main techniques; laparoscopic-assisted TaTME or NOTES TaTME, and Pure TaTME [31-34]. Laparoscopic-assisted TaTME includes two surgical fields, abdominal and transanal. A one-team approach involves sequential phases, where either abdominal or transanal dissection is performed first. TaTME can also be performed by two surgical teams working simultaneously; one team performs the abdominal dissection while the other team performs the transanal part.

The essential steps of laparoscopic-assisted TaTME are: (1) Insertion of transanal platform (TEMS or SILS port) and the creation of pneumorectum, (2) Occlusion of rectum distal to the rectal lesion via purse string, (3) Transanal dissection of lower and mid rectum mesorectal, (4) Abdominal approach with laparoscopic mobilization of the left colon and if required of the splenic flexure, (5) Laparoscopic isolation and transection of inferior mesenteric vessels, (6) Transabdominal dissection of the upper rectum mesorectal, (7) Joining of abdominal and transanal surgical fields, (8) Completion of the anterior resection and removal of specimen, and (9) Creation of colorectal or coloanal anastomosis.

The transanal phase begins with the insertion of a single-port device, commonly with either SILS port or TEMS platform. From here, the tumor can be visualized and purse string suture is performed $1 \mathrm{~cm}$ to $5 \mathrm{~cm}$ below the distal tumor margin, depending on the location of the tumor in relation to the anal sphincter. Application of purse string will prevent spillage of bowel content as to minimize bacterial infection and prevent possible tumor cell spillage during surgery. Distal to the purse string, full thickness rectal wall dissection is made to gain entry into the perirectal space. The ability to clearly identify the distal resection margins at the beginning of surgery is a key feature of TaTME. This is thought to improve oncological resection margin quality and increase the chance for sphincter preservation. Next, a mesorectal excision is performed from distal to proximal direction. Careful consideration is made not to breach the rectoprostatic/rectovaginal fascia or the mesorectal fascia. The surgeon must be cogniscent of the curvature of the sacrum as well as the presence of neurovascular structures on the lateral sides. Posterior dissection, if performed too deep beyond the presacral space, can lead to injury of the sacral venous plexus leading to significant blood loss.

The specimen can be extracted through an abdominal incision through the ileostomy site, mid-line incision, or Pfannenstiel incision. In patients with a small rectal tumor or non-bulky mesorectum, the specimen can also be removed transanally. This approach would theoretically decrease the risk of an incisional hernia after TaTME as compared to open surgery.

NOTES TATME or Pure TaTME does not involve an abdominal incision, instead, the entire procedure is performed transanally with a "down to up" approach and the specimen is extracted via the anus [34,35]. 
The colorectal anastomosis is generally performed using a circular stapler or the EEA ${ }^{\mathrm{TM}}$ hemorrhoid stapler. For resection of very low rectal cancer, a hand-sewn coloanal anastomosis is often preferred. There have been four different anastomotic techniques that have been described in an excellent paper by Penna et al. [36].

\section{Methods}

\section{Search strategy}

A comprehensive search of the PubMed database was performed using the following subject heading and keywords: rectal neoplasm, adenocarcinoma, rectum, treatment outcome, adult, mesorectal, transanal endoscopic microsurgery, transanal endoscopic surgery, TaTME, complications and outcomes.

\section{Inclusion and exclusion criteria}

Prospective or retrospective clinical case studies on patients affected by rectal adenocarcinomas undergoing mesorectal excision were included. Exclusion criteria were: case reports, systematic reviews, meta-analysis, studies on patients affected by recurrent rectal cancers, patients younger than 18 years, treatment of benign rectal tumors or other malignancies such as melanomas, neuroendocrine tumors, gastrointestinal stromal tumors, sarcomas or other non-epithelial malignancies. Studies comparing TaTME to LapTME, duplicate studies and scientific papers in languages other than English were also excluded (Figure 1) [37]. The references of each included study were examined to ensure additional studies were not overlooked. Each reference was manually retrieved from PubMed and its abstract reviewed. No additional studies were identified from assessing the reference of included study.

\section{Data collection}

Data retrieved from each included study were: first author's last name, year of publication, total number of participants, patient demographics (age, BMI, gender, ratio, the American Society of Anesthesiologist (ASA) status, and neoadjuvant therapy), perioperative details (operative time, operative team approach, type of abdominal assistance, type of transanal platform, conversion to open surgery, and intraoperative complications, postoperative complications, length of stay), histopathological outcomes (circumferential resection margin (CRM) quality/ positivity, distal resection margin (DRM) margin/positivity, and number of lymph node harvested), and short-term oncological outcomes (follow-up period, local recurrence and distal recurrence).

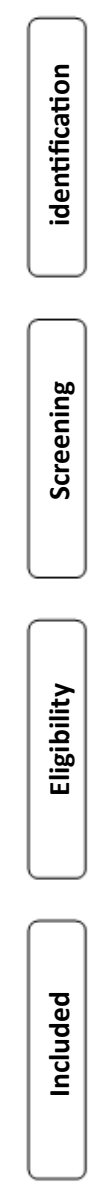

Figure 1
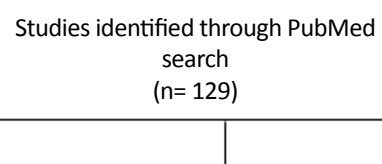

Studies identified through manual search of references $(n=0)$

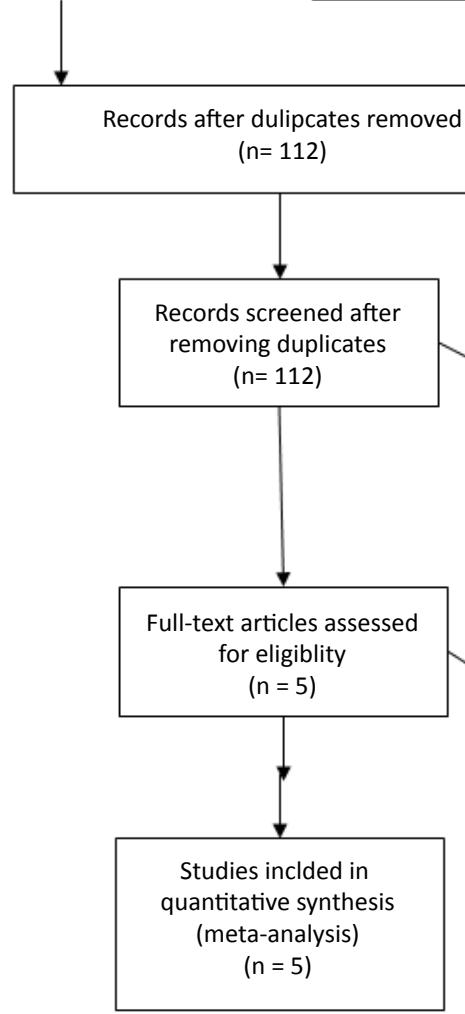

Studies inclded in

$(\mathrm{n}=5)$

Flowchart representing the inclusion and exclusion of studies using preferred reporting items for systematic reviews and meta-analyses (PRISMA). 


\section{Results}

\section{Patient demographics}

In total, 378 patients underwent TaTME (Table 1) [33,38-41]. The study from Lacy et al. presented the largest homogenous singlecenter prospective study with 140 patients [38]. With exception of one patient diagnosed with a large sessile villous adenoma (>8 $\mathrm{cm}$ ) with multiple foci of adenocarcinoma in situ, the rest of the study population had rectal adenocarcinomas. The age of the patients ranged from 35 to 87 years. The overall male to female ratio was 1.6:1. The mean/median BMI ranged from 25.2 to 27.5 (range, 19.4 to 42 ). The majority of patients were ASA class II. The neoadjuvant therapy varied from different studies ranging from $33.3 \%$ to $86 \%$. Overall, 285 out of 378 patients $(75.4 \%)$ underwent neoadjuvant therapy.

\section{Intraoperative characteristics}

The majority of patients who had abdominal assistance were operated using laparoscopic multi-ports (Table 2). TaTME was mainly performed with TAMIS platform via GeIPOINT Path transanal platform or SILS port. The mean/median operative time ranged from 166 to 270 minutes (range, 60 to 495). Of the 378 patients included in this review, 8 patients $(2.1 \%)$ required conversion to open surgery. The reasons for conversion included fixation of the anterior rectum to adjacent structures, intra-op cardiac complications, severe intra-abdominal adhesions, and technical difficulty due to obesity (BMI=32 and 37 ), and locally advanced tumors causing concern for the resection margin status. The mean/median length of stay varied between 4.5 to 10 days (range 3 to 41 ). In total, 8 cases (2.1\%) of intra-operative complications were reported. Veltcamp Helbach et al. [40] reported 5 cases with 2 cases of hemorrhage and 3 cases of rectal perforation that required repair with transanal suturing. Burke et al. [41] reported 3 intra-operative complications (two urethral injuries and one internal iliac vessel injury). Out of these 3 injuries, only one case of urethral injury occurred during the transanal phase. Amongst included studies, the rate of post-operative complications ranged from $26 \%$ to $39 \%$. Most commonly described post-operative complications included anastomotic leak, intraabdominal/pelvic abscess, ileus/bowel obstruction, and urinary retention/infection. Three out of five studies summarized in this review reported their complications using Clavien-Dindo (CD) classification (Table 3) [33,38,40,42]. Minor complications (CD classification I and II) ranged from $15.7 \%$ to $26.3 \%$, whereas major complications (CD classification $\mathrm{III+V)}$ ranged from $10 \%$ to $15.7 \%$. Overall, there were 3 cases $(0.8 \%)$ of postoperative mortality (CD classification V). One case of mortality, reported by Veltcamp Helbach et al. [40], was due to severe sepsis from an anastomotic leak. Two cases of mortality were reported by Huscher et al. [33], where one patient passed away from a pulmonary embolism and another patient had an acute peritonitis leading to death from multi-organ failure.

\section{Outcomes}

Histopathological and oncological outcomes are reported in Table 4. The quality of CRM was graded according to Quirke classification in complete, near incomplete or incomplete (Table 5) [43]. Complete CRM was reported in $72 \%$ to $97.1 \%$ of patients. Positive CRM ranged from $0 \%$ to $6.4 \%$. DRM resection margin ranged from mean/median value of $10 \mathrm{~mm}$ to $37.1 \mathrm{~mm}$. Three out of 5 studies reported DRM positivity status. The only positive DRM was observed in 1 patient [41]. The mean/median numbers of lymph node harvested were 12 to 20 (range 6 to 30). The oncologic outcomes were reported by 4 out of 5 studies. The median follow-up period ranged from 15.1 to 29 months (range, 1-52 months). Local recurrence was observed in the range of $1.9 \%$ to $4 \%$ of patients and distal recurrence rate ranged from $3.9 \%$ to $14.5 \%$. The survival outcomes were quantified by 2 out of 5 studies. Lacy et al. [38] reported survival rate of $97.1 \%$ and cancer related death rate of $2.1 \%$ at the end of the followup period (15.0 months). Tuech et al. [39] estimated a 5-year disease-free survival rate of $94.2 \%$ based on 2 metastatic and 1 local cancer recurrence observed in their study.

\section{Discussion}

Several technical challenges are associated with laparoscopic treatment of distal rectal tumors in patients with narrow pelvis or obesity. Limited visualization and insufficient maneuverability preclude safe dissections and the appropriate firing of laparoscopic staples leading to conversion to open surgery.

Table 1. Summary of clinical characteristic of the patient populations of all studies included in this mini review.

\begin{tabular}{|c|c|c|c|c|c|c|c|}
\hline Authors & Year & $\mathbf{N}$ & Age (range) & $\begin{array}{l}\text { Gender } \\
\text { (m:f) }\end{array}$ & $\begin{array}{c}\text { BMI } \\
\text { (Range) }\end{array}$ & $\begin{array}{c}\text { ASA } \\
\text { Class (\%) }\end{array}$ & $\begin{array}{c}\text { Neoadjuvant Therapy } \\
\text { n (\%) }\end{array}$ \\
\hline Lacy et al. [38] & 2015 & 140 & $65.5+/-12.7^{*}$ & 89: 51 & $25.2+/-3.9^{*}$ & $\begin{array}{c}\text { I - } 8(5.7) \text { II - } 117(83.5) \text { III - } 15 \\
(10.8)\end{array}$ & $\begin{array}{c}94 \text { (67.1) CRT; } 90 \text { (64.2) Chemo } \\
3 \text { (2.1) RT -1 (0.7) }\end{array}$ \\
\hline Huscher et al. [33] & 2016 & 102 & $67.6(35-87)$ & 56: 46 & $25.3+/-4.1^{*}$ & $\begin{array}{c}\text { I - } 3(2.9) \text { II }-37(36.3) \text { III - } 62 \\
(60.8)\end{array}$ & $34(33.3)$ \\
\hline Helbach et al. [40] & 2016 & 80 & $66.5(42-86)$ & 48: 32 & $27.5(19.4-40)$ & $\begin{array}{c}\text { I - } 15(18.8) \text { II - } 53(66.2) \text { III - } \\
12(15)\end{array}$ & $\begin{array}{c}67 \text { (83.8) CRT; } 26 \text { (32.5) RT; } 39 \\
(48.8)\end{array}$ \\
\hline Tuech et al. [39] & 2015 & 56 & $65^{a}(39-83)$ & 41: 15 & $27^{a}(20-42)$ & $\begin{array}{c}\text { I - } 5 \text { (8.9) II - } 40 \text { (71.5) III -11 } \\
(19.6)\end{array}$ & 47 (83.9) \\
\hline Burke et al. [41] & 2015 & 50 & $56.5^{\mathrm{a}}(50-65)$ & $30: 20$ & $26.0^{\mathrm{a}}(22.7-31.2)$ & I/II 36(72) III/IV - 14(28) & $43(86)$ \\
\hline
\end{tabular}

$\mathrm{N}$ : Number of participants; m:f: Male to female ratio; BMI: Body mass index; ASA: The American Society of Anesthesiologists; CRT: Chemoradiation therapy; Chemo: chemotherapy; RT: Radiation therapy

*Mean +/- standard deviation

a Median value 
Table 2. Summary of TaTME clinical cases: operative characteristics, postoperative complications and hospital length of stay.

\begin{tabular}{|c|c|c|c|c|c|c|c|c|c|c|c|}
\hline Authors & Year & $\mathbf{N}$ & $\begin{array}{l}\text { Operative } \\
\text { Time }\end{array}$ & $\begin{array}{l}\text { Operative } \\
\text { Team }\end{array}$ & $\begin{array}{l}\text { Abdominal } \\
\text { Assistance }\end{array}$ & $\begin{array}{l}\text { Transanal } \\
\text { platform }\end{array}$ & \begin{tabular}{|c|}
$\begin{array}{c}\text { Conversion } \\
\text { Rate }\end{array}$ \\
n (\%)
\end{tabular} & $\begin{array}{l}\text { Intraoperative } \\
\text { Complications }\end{array}$ & $\begin{array}{c}\text { Post- } \\
\text { operative } \\
\text { complication } \\
\text { (\%) }\end{array}$ & $\begin{array}{c}\text { Post-operative } \\
\text { complication } \\
\text { Clavien-Dindo } \\
\text { (\%) }\end{array}$ & $\begin{array}{l}\text { Length of } \\
\text { Stay, days } \\
\text { (range) }\end{array}$ \\
\hline $\begin{array}{l}\text { Lacy et al. } \\
\text { [38] }\end{array}$ & 2015 & 140 & $166+/-57 *$ & Two-team & Multi-port & $\begin{array}{l}\text { GelPOINT } \\
\text { Path } \\
\text { Transanal }\end{array}$ & 0 & 0 & $48(34.3)$ & $\begin{array}{c}\text { I/II - } 34(24.2) \\
\text { III/IV - } 14(10) \\
\text { V - O(0) }\end{array}$ & $6(3-39)$ \\
\hline $\begin{array}{l}\text { Huscher et } \\
\text { al. [33] }\end{array}$ & 2016 & 102 & $\begin{array}{c}185(60- \\
480)\end{array}$ & $\begin{array}{l}\text { Single- } \\
\text { team }\end{array}$ & Multi-port & $\begin{array}{l}\text { GeIPOINT } \\
\text { path } \\
\text { transanal, } \\
\text { SILS port, } \\
\text { or TEM } \\
\text { rectoscope }\end{array}$ & 0 & 0 & $34(33.3)$ & $\begin{array}{c}I / I I-16(15.7) \\
\text { III/IV - } 16 \\
(15.7) \mathrm{V}-2 \\
(1.9)\end{array}$ & $9.6(4-69)$ \\
\hline $\begin{array}{c}\text { Veltcamp } \\
\text { Helbach et } \\
\text { al. [40] }\end{array}$ & 2016 & 80 & $\begin{array}{c}204(91- \\
447)\end{array}$ & $\begin{array}{l}\text { Single- } \\
\text { team }\end{array}$ & $\begin{array}{l}\text { Multi-port or } \\
\text { Single-port }\end{array}$ & $\begin{array}{l}\text { GelPOINT } \\
\text { Path } \\
\text { Transanal } \\
\text { or SILS } \\
\text { port }\end{array}$ & $4(5)$ & $\begin{array}{l}\text { Hemorrhage }-2 \\
\text { Rectal perf - } 3\end{array}$ & 31 (39) & $\begin{array}{c}\mathrm{I} / \mathrm{II}-21(26.3) \\
\mathrm{III} / \mathrm{IV}-9(11.3) \\
\mathrm{V}-1(1.3)\end{array}$ & $8(3-41)$ \\
\hline $\begin{array}{l}\text { Tuech et } \\
\text { al. [39] }\end{array}$ & 2015 & 56 & $\begin{array}{c}270^{a}(150- \\
195)\end{array}$ & NR & $\begin{array}{c}\text { Multi-port or } \\
\text { Single-port }\end{array}$ & $\begin{array}{l}\text { GeIPOINT } \\
\text { path } \\
\text { transanal, } \\
\text { SILS port, } \\
\text { or endorec } \\
\text { Trocar }\end{array}$ & $3(7.3)$ & 0 & $14(26)$ & NR & $10^{a}(6-21)$ \\
\hline $\begin{array}{l}\text { Burke et } \\
\text { al. [41] }\end{array}$ & 2015 & 50 & $\begin{array}{c}267^{\mathrm{a}}(227- \\
331)\end{array}$ & $\begin{array}{l}\text { Two-team } \\
\text { or Single- } \\
\text { team }\end{array}$ & $\begin{array}{c}\text { Open, } \\
\text { Laparoscopic } \\
\text { or Robotic }\end{array}$ & $\begin{array}{l}\text { GelPOINT } \\
\text { Path } \\
\text { Transanal }\end{array}$ & $1(2.2)^{b}$ & $\begin{array}{l}\text { Urethral injury - } \\
2^{c} \text { Internal iliac } \\
\text { vessel injury - } 1\end{array}$ & (36) & NR & $4.5^{a}(4-8)$ \\
\hline
\end{tabular}

$\mathrm{N}$ : number of participants; NR: not reported

*Mean +/- standard deviation; ${ }^{a}$ Median value; ${ }^{\mathrm{b}}$ Total number of patient 46 , as 4 patients had planned open surgery wit TaTME; ${ }^{\mathrm{C} O n e}$ urethral injury occurred during transanal phase.

Table 3. Clavien-Dindo classification for postoperative complications [42].

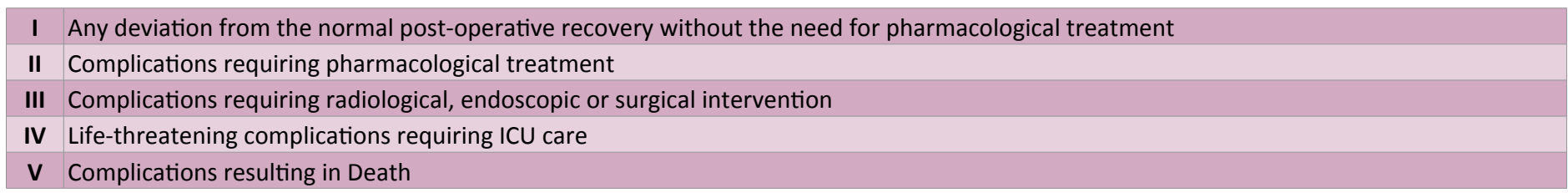

Table 4. Summary of TaTME clinical cases: histopathological characteristics and oncological outcomes.

\begin{tabular}{|c|c|c|c|c|c|c|c|c|c|c|}
\hline Authors & Year & $\mathbf{N}$ & Quality \% & $\begin{array}{c}\text { CRM } \\
\begin{array}{c}\text { Positivity } \\
\%\end{array}\end{array}$ & $\begin{array}{c}\text { DRM } \\
\text { mm } \\
\text { (range) }\end{array}$ & $\begin{array}{c}\text { DRM } \\
\begin{array}{c}\text { Positivity } \\
\%\end{array}\end{array}$ & $\begin{array}{c}\text { Lymph node } \\
\text { harvested } \\
\text { (range) }\end{array}$ & $\begin{array}{l}\text { Median } \\
\text { Follow up } \\
\text { period, } \\
\text { months } \\
\text { (range) }\end{array}$ & $\begin{array}{l}\text { Local } \\
\text { Recurrence } \\
(\%)\end{array}$ & $\begin{array}{c}\text { Distal } \\
\text { Recurrence }\end{array}$ \\
\hline Lacy et al. [38] & 2015 & 140 & $\begin{array}{c}\text { Complete: } 97.1 \text { Near } \\
\text { complete: } 2.1\end{array}$ & $6.4^{\mathrm{a}}$ & $28+/-2.1^{*}$ & 0 & $14.7+/-6.8^{*}$ & $15.1(7-20)^{d}$ & $3(2.3)$ & $10(7.6)$ \\
\hline $\begin{array}{c}\text { Huscher et al. } \\
\text { [33] }\end{array}$ & 2016 & 102 & $\begin{array}{c}\text { Complete: } 97.1 \text { Near } \\
\text { complete: } 2.9\end{array}$ & $5.4^{\mathrm{b}}$ & $\begin{array}{c}37.1+/- \\
28.5^{*}\end{array}$ & 0 & $20+/-11.7^{*}$ & NR & NR & NR \\
\hline $\begin{array}{c}\text { Veltcamp Helbach } \\
\text { et al. [40] }\end{array}$ & 2016 & 80 & $\begin{array}{c}\text { Complete: } 88 \text { Near } \\
\text { complete: } 9\end{array}$ & $2.5^{b}$ & NR & NR & $14(6-30)$ & NR & $2(2.5)$ & 0 \\
\hline Tuech et al. [39] & 2015 & 56 & $\begin{array}{l}\text { Complete: } 84 \text { Near } \\
\text { complete: } 16\end{array}$ & $5.4^{\mathrm{a}}$ & $10^{c}(3-40)$ & NR & $12^{c}(7-29)$ & $29(18-52)$ & $1(1.9)$ & $2(3.9)$ \\
\hline Burke et al. [41] & 2015 & 50 & $\begin{array}{l}\text { Complete: } 72 \text { Near } \\
\text { complete: } 26\end{array}$ & $4^{b}$ & $10^{c}(5-17)$ & 2 & $18^{\mathrm{c}}(12-23.8)$ & $\begin{array}{l}15.1(9.7- \\
20.4)\end{array}$ & $2(4)$ & $7(14.5)^{\mathrm{e}}$ \\
\hline
\end{tabular}

$\mathrm{N}$ : Number of participants; NR: Not reported; CRM: Circumferential resection margin; DRM: Distal resection margin

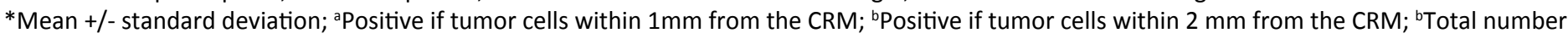
of patient 46, as 4 patients had planned open surgery wit TaTME; ${ }^{C}$ One urethral injury occurred during transanal phase; ${ }^{\mathrm{d}}$ Excluded 9 patients with stage IV lesion; excluded 2 patinets with known stage IV lesion 
Table 5. Quirke classification for grading the quality of the mesorectum for total mesorectal excisions [44].

\begin{tabular}{|c|c|c|c|c|}
\hline & Mesorectum & Defects & \multicolumn{2}{c|}{ Coning } \\
\hline Complete & Smooth and intact & Defect is not deeper than $5 \mathrm{~mm}$ & None & Regular, smooth \\
\hline Nearly complete & Irregular, moderate bulk & Muscularis propria not visible & Moderate & Irregular \\
\hline Incomplete & Very irregular, little bulk & Defect down to muscularis propria & Moderate to marked & Irregular \\
\hline
\end{tabular}

Inadequate visualization, especially during the dissection of the anterior rectal wall may also lead to positive margins and poor oncological outcomes. A down to up approach via TaTME technique may overcome all these challenges faced during laparoscopic rectal surgery. The studies presented in this review paper support the safety and feasibility of TaTME for middle and low rectal adenocarcinomas [33,38-41].

There was an association between shorter operative times and larger number of participants in all studies included in this review. This may be the result of the learning curve necessary to reach a high level of proficiency that comes with a considerable number of surgical cases and the use of two surgical teams approach. Huscher et al. [33], and Veltcamp Helbach et al. [40] reported that, even when a single-team approach is used, TaTME can be accomplished with shorter operative times (median time, 185 - 204 minutes) in comparison to the LapTME (COLOR II trial: median time 240 minutes) $[13,33,40]$. The conversion rate for TaTME was also quite low ( $0 \%$ to $7.3 \%$ ) as compared to the rate of $16 \%$ observed during LapTME during the COLOR II trial [13]. In addition, intra-operative complication rates for TaTME (2.6\%) was significantly lower than $14 \%$ observed in patients treated with LapTME or $13 \%$ in patients undergoing open TME described in the CLASSIC trial [44]. In addition, a large meta-analysis by Arezzo et al. [45] comparing laparoscopic to open surgery for rectal cancer indicated a mortality rate of $1 \%$ for laparoscopic group and $2.4 \%$ for open surgery group.

As TaTME is still a relatively new technique, there is a possibility of encountering new and unexpected types of complications during the learning phase. As part of the surgery requires placing pursestring of the rectum, there is an increased risk of peritoneal/ pelvic contamination. A study by Velthuis et al. [46] in 2015 showed that 9 out of 23 (39\%) patients had positive abdominal cultures after TaTME. Out of these 9 patients, 4 developed presacral abscess with or without anastomotic dehiscence. The impact of perioperative care (e.g., use of preoperative bowel preparation and oral antibiotics, rectal lavage with anti-bacterial solution etc.) on the rate of pelvic abscess formation needs further investigations. Concerns have also been raised in earlier studies regarding urinary morbidity (urethral injury, urinary retention, and infection) after TaTME procedure [15]. However, Tuech et al. [39] indicated that although 5 pts out of 56 (8.9\%) experienced urinary retention requiring short-term urethral catheterization, these patients did not experience any long term urinary dysfunction [39]. Another study by Chen et al. [47] who performed TaTME with a trial of expedited foley removal (on post-operative day 2) did not observe any incidence of urinary dysfunction.

The majority of complications published for TaTME pertain to short-term outcomes (within 30 days). Study regarding functional outcome after TaTME is still quite limited. Tuech et al. [39] did inquire about fecal continence and sexual function after TaTME. Severe fecal incontinence was observed in $5.7 \%$ of patients who required the creation of a colostomy, whereas $28 \%$ of patients reported difficult stool evacuation. In terms of sexual function, $11.2 \%$ of sexually active patients reported severe impotence. Whether TaTME surgery has a significant impact on ileostomy closure rate, anastomotic stricture, fecal continence, or sexual function is still unclear.

The oncological quality of TaTME was also comparable to published data from LapTME or open TME. In COLOR II and CLASSIC trial, completeness of TME was reported to be $66 \%$ to $88 \%$ for the open surgeries and $77 \%$ to $84 \%$ for the laparoscopic approach $[6,14,44]$. In comparison, CRM completeness in TaTME reported by studies included in this review ranged from $72 \%$ to 97\%. CRM positive status in TaTME study was comparable to the reports from the CLASSIC trial (7\% laparoscopic and 5\% open approach). Whether the higher quality of mesorectal resection observed in TaTME patients will translate into lower local recurrences and longer survival is uncertain. The range of local recurrence reported by included study in this review was $1.9 \%$ to $2.5 \%$, which is lower than $5 \%$ reported in COLOR II trial [6].

\section{Comparative study: TaTME versus lapTME}

Although studies described in this review showed promising results for TaTME in terms of oncological resection quality and short-term outcomes, it is still unclear whether this novel technique is equivalent or superior to LapTME. A small number of comparative studies, mainly composed of matched case-control design, have been published comparing the outcomes of TaTME and LapTME. Recently, Ma et al. performed a meta-analysis on seven studies [48]. Overall, 573 subjects were included with 270 patients treated with TaTME and 303 patients treated with LapTME. Peri-operatively, TaTME group showed 23 minutes shorter operative time $(P<0.01)$ as well as lower conversion rate $(\mathrm{OR}=0.29,95 \% \mathrm{Cl}=0.11-0.81, \mathrm{P}=0.02)$ as compared to LapTME group while the length of hospital stay showed no difference between the two groups. In the included comparative studies, TaTME had a significantly lower rate of post-operative complications $(\mathrm{OR}=0.65,95 \% \mathrm{Cl}=0.45-0.95, \mathrm{P}=0.03)$. However, the rate of anastomotic leak, ileus, and urinary morbidity was similar. There was no statistically significant difference in re-admission rates between the groups. TaTME patients showed higher rate of complete mesorectal resection as compared to LapTME (83.4\% versus $73.4 \%$, respectively; $\mathrm{OR}=1.75,95 \% \mathrm{Cl}=1.02-3.01, \mathrm{P}=0.04)$. Additionally, fewer patients had a positive CRM within the TaTME group (OR=0.39, 95\% $\mathrm{Cl}=0.17-0.86, \mathrm{P}=0.02)$. There was no statistical difference between TaTME and LapTME in regards to a number of lymph node harvested, length and positivity of distal resection margin. Overall, TaTME, as compared to LapTME, 
appears to achieve higher quality of mesorectal excision and comparable post-operative complications, admission length and readmission rates.

\section{Future considerations}

Selection biases as well as heterogeneity of the quality of surgical instruments are intrinsic to the design of observational studies included in our review. Although there is a clear need for randomized control trials to directly compare the outcomes of TaTME and LapTME, several considerations can be drawn from the current evidence. The first one is that TaTME provides similar oncological outcomes to LapTME and open TME. Second is that TaTME can be performed safely, and with low perioperative morbidity. Although precise indications and contraindications for TaTME have not been established yet, current evidence suggests that TaTME would be most suitable for mid to low rectal cancer in obese/male patients who cannot be treated with local excision. On the other hand, locally advanced tumors (T4), possible tumor invasion in the sphincter, or threatened CRM status will be best served by open surgery.

As TaTME requires expertise in both laparoscopic and transanal techniques, wide implementation may be difficult and a standardized cadaver/animal courses, as well as in-hospital proctoring will be necessary before being adopted by general and colorectal surgeons.

Lastly, cost effectiveness of TaTME still needs to be investigated. The direct upfront cost of TaTME will is higher if a rigid TEMS platform system is utilized as compared to TAMIS. Two-team approach also requires more staff and may also increase the cost of the procedure, although costs may be offset by a shorter operating time. If TaTME can lead to shorter length of stay or lower complication rate, then it may result in indirect cost saving as well. To answer most of these questions, a large randomized controlled study (COLOR III) is underway to compare TaTME to LapTME for treatment of patients with mid and low rectal adenocarcinoma [7].

\section{Conclusion}

TaTME offers exciting new future for treatment of mid to lower rectal cancer surgery. So far, current studies have shown shortterm safety and feasibility of TaTME. Ultimately, randomized control trials and longer follow-ups will be required to prove the oncological safety and effectiveness of TaTME. 


\section{References}

1 Heald RJ (2003) Total mesorectal exsicion (TME). Acta Chir lugosl 47: 17-18.

2 Heald RJ, Husband EM, Ryall RD (1982) The mesorectum in rectal cancer surgery--the clue to pelvic recurrence. Br J Surg 69: 613-616.

3 MacFarlane JK, Ryall RD, Heald RJ (1993) Mesorectal excision for rectal cancer. Lancet 341: 457-460.

4 Jeong SY, Park JW, Nam BH, Kim S, Kang SB, et al. (2014) Open versus laparoscopic surgery for mid-rectal or low-rectal cancer after neoadjuvant chemoradiotherapy (COREAN trial): survival outcomes of an open-label, non-inferiority, randomised controlled trial. Lancet Oncol 15: 767-774.

5 Kang SB, Park JW, Jeong SY, Nam BH, Choi HS, et al. (2010) Open versus laparoscopic surgery for mid or low rectal cancer after neoadjuvant chemoradiotherapy (COREAN trial): short-term outcomes of an open-label randomised controlled trial. Lancet Oncol 11: 637-645.

6 Bonjer HJ, Deijen CL, Haglind E, Group CIS (2015) A Randomized Trial of Laparoscopic versus Open Surgery for Rectal Cancer. N Engl J Med 373: 194.

7 Deijen CL, Velthuis S, Tsai A, Mavroveli S, de Lange-de Klerk ES, et al. (2016) COLOR III: a multicentre randomised clinical trial comparing transanal TME versus laparoscopic TME for mid and low rectal cancer. Surg Endosc 30: 3210-3215.

8 Bonjer HJ, Deijen CL, Abis GA, Cuesta MA, van der Pas MH, et al. (2015) A randomized trial of laparoscopic versus open surgery for rectal cancer. N Engl J Med 372: 1324-1332.

9 Lujan J, Valero G, Hernandez Q, Sanchez A, Frutos MD, et al. (2009) Randomized clinical trial comparing laparoscopic and open surgery in patients with rectal cancer. Br J Surg 96: 982-989.

10 Stevenson AR, Solomon MJ, Lumley JW, Hewett P, Clouston AD, et al. (2015) Effect of Laparoscopic-Assisted Resection vs Open Resection on Pathological Outcomes in Rectal Cancer: The ALaCaRT Randomized Clinical Trial. JAMA 314: 1356-1363.

11 Fleshman J, Branda M, Sargent DJ, Boller AM, George V, et al. (2015) Effect of Laparoscopic-Assisted Resection vs Open Resection of Stage II or III Rectal Cancer on Pathologic Outcomes: The ACOSOG Z6051 Randomized Clinical Trial. JAMA 314: 1346-1355.

12 Ng SS, Leung KL, Lee JF, Yiu RY, Li JC, et al. (2009) Long-term morbidity and oncologic outcomes of laparoscopic-assisted anterior resection for upper rectal cancer: ten-year results of a prospective, randomized trial. Dis Colon Rectum 52: 558-566.

13 van der Pas MH, Haglind E, Cuesta MA, Furst A, Lacy AM, et al. (2013) Laparoscopic versus open surgery for rectal cancer (COLOR II): shortterm outcomes of a randomised, phase 3 trial. Lancet Oncol 14: 210218.

14 Jayne DG, Thorpe HC, Copeland J, Quirke P, Brown JM, et al. (2010) Five-year follow-up of the Medical Research Council CLASICC trial of laparoscopically assisted versus open surgery for colorectal cancer. Br J Surg 97: 1638-1645.

15 Sylla P, Bordeianou LG, Berger D, Han KS, Lauwers GY, et al. (2013) A pilot study of natural orifice transanal endoscopic total mesorectal excision with laparoscopic assistance for rectal cancer. Surg Endosc 27: 3396-3405.

16 De Lacy AM, Rattner DW, Adelsdorfer C, Tasende MM, Fernandez M, et al. (2013) Transanal natural orifice transluminal endoscopic surgery (NOTES) rectal resection: "down-to-up" total mesorectal excision (TME)--short-term outcomes in the first 20 cases. Surg Endosc 27: 3165-1372.

17 Heald RJ (2013) A new solution to some old problems: transanal TME. Tech Coloproctol 17: 257-258.

18 Buess G, Theiss R, Hutterer F, Pichlmaier H, Pelz C, et al. (1983) Transanal endoscopic surgery of the rectum - testing a new method in animal experiments. Leber Magen Darm 13: 73-77.

19 Marks GJ, Marks JH, Mohiuddin M, Brady L (1998) Radical Sphincter preservation surgery with coloanal anastomosis following highdose external irradiation for the very low lying rectal cancer. Recent Results Cancer Res 146: 161-174.

20 Sylla P, Willingham FF, Sohn DK, Gee D, Brugge WR, et al. (2008) NOTES rectosigmoid resection using transanal endoscopic microsurgery (TEM) with transgastric endoscopic assistance: a pilot study in swine. J Gastrointest Surg. 12: 1717-1723.

21 Buess G, Hutterer F, Theiss J, Bobel M, Isselhard W, et al. (1984) A system for a transanal endoscopic rectum operation. Chirurg 55: 677-680.

22 Atallah S, Albert M, DeBeche-Adams T, Nassif G, Polavarapu H, et al. (2013) Transanal minimally invasive surgery for total mesorectal excision (TAMIS-TME): a stepwise description of the surgical technique with video demonstration. Tech Coloproctol 17: 321-325.

23 Rega D, Pace U, Niglio A, Scala D, Sassaroli C, et al. (2016) TAMIS for rectal tumors: advancements of a new approach. Updates Surg 68: 93-97.

24 Whiteford MH, Denk PM, Swanstrom LL (2007) Feasibility of radical sigmoid colectomy performed as natural orifice translumenal endoscopic surgery (NOTES) using transanal endoscopic microsurgery. Surg Endosc 21: 1870-1874.

25 Tan KY, Maeda T, Konishi F (2009) Multimedia article. Transanal endoscopic resection of the rectum with high ligation on a swine model--a novel type of natural orifice endoscopic surgery. Dis Colon Rectum 52: 2045-2047.

26 Sohn DK, Jeong SY, Park JW, Kim JS, Hwang JH, et al. (2011) Comparative study of NOTES rectosigmoidectomy in a swine model: E-NOTES vs. P-NOTES. Endoscopy 43: 526-532.

27 Sylla P, Sohn DK, Cizginer S, Konuk Y, Turner BG, et al. (2010) Survival study of natural orifice translumenal endoscopic surgery for rectosigmoid resection using transanal endoscopic microsurgery with or without transgastric endoscopic assistance in a swine model. Surg Endosc 24: 2022-2230.

28 Trunzo JA, Delaney CP (2010) Natural orifice proctectomy using a transanal endoscopic microsurgical technique in a porcine model. Surg Innov 17: 48-52.

29 Bravo R, Fernandez-Hevia M, Jimenez-Toscano M, Flores LF, de Lacy B, et al. (2016) Transanal Hartmann reversal: a new technique. Surg Endosc 30: 2628-2631.

30 Tasende MM, Delgado S, Jimenez M, Del Gobbo GD, FernandezHevia M, et al. (2015) Minimal invasive surgery: NOSE and NOTES in ulcerative colitis. Surg Endosc 29: 3313-3318.

31 Marks JH, Lopez-Acevedo N, Krishnan B, Johnson MN, Montenegro GA, et al. (2016) True NOTES TME resection with splenic flexure release, high ligation of IMA, and side-to-end hand-sewn coloanal anastomosis. Surg Endosc 30: 4626-4631.

32 Chouillard E, Regnier A, Vitte RL, Bonnet BV, Greco V, et al. (2016) 
Transanal NOTES total mesorectal excision (TME) in patients with rectal cancer: Is anatomy better preserved? Tech Coloproctol 20: 537-544.

33 Huscher CG, Tierno SM, Romeo V, Lirici MM (2016) Technologies, technical steps, and early postoperative results of transanal TME. Minim Invasive Ther Allied Technol 8: 1-10.

34 Leroy J, Barry BD, Melani A, Mutter D, Marescaux J (2013) No-scar transanal total mesorectal excision: the last step to pure NOTES for colorectal surgery. JAMA Surg 148: 226-230.

35 Chouillard E, Chahine E, Khoury G, Vinson-Bonnet B, Gumbs A, et al. (2014) NOTES total mesorectal excision (TME) for patients with rectal neoplasia: a preliminary experience. Surg Endosc 28: 31503157.

36 Penna M, Knol JJ, Tuynman JB, Tekkis PP, Mortensen NJ, et al. (2016) Four anastomotic techniques following transanal total mesorectal excision (TaTME). Tech Coloproctol 20: 185-191.

37 Panic N, Leoncini E, de Belvis G, Ricciardi W, Boccia S (2013) Evaluation of the endorsement of the preferred reporting items for systematic reviews and meta-analysis (PRISMA) statement on the quality of published systematic review and meta-analyses. PLoS One 8: e83138.

38 Lacy AM, Tasende MM, Delgado S, Fernandez-Hevia M, Jimenez M, et al. (2015) Transanal Total Mesorectal Excision for Rectal Cancer: Outcomes after 140 Patients. J Am Coll Surg 221: 415-423.

39 Tuech JJ, Karoui M, Lelong B, De Chaisemartin C, Bridoux V, et al. (2015) A step toward NOTES total mesorectal excision for rectal cancer: endoscopic transanal proctectomy. Ann Surg 261: 228-233.

40 Veltcamp Helbach M, Deijen CL, Velthuis S, Bonjer HJ, Tuynman JB, et al. (2016) Transanal total mesorectal excision for rectal carcinoma: short-term outcomes and experience after 80 cases. Surg Endosc 30: 464-470.
41 Burke JP, Martin-Perez B, Khan A, Nassif G, de Beche-Adams T, et al. (2016) Transanal total mesorectal excision for rectal cancer: early outcomes in 50 consecutive patients. Colorectal Dis 18: 570-577.

42 Clavien PA, Barkun J, de Oliveira ML, Vauthey JN, Dindo D, et al. (2009) The Clavien-Dindo classification of surgical complications: five-year experience. Ann Surg 250: 187-196.

43 Nagtegaal ID, van de Velde CJ, van der Worp E, Kapiteijn E, Quirke $P$, et al. (2002) Macroscopic evaluation of rectal cancer resection specimen: clinical significance of the pathologist in quality control. J Clin Oncol 20: 1729-1734.

44 Guillou PJ, Quirke P, Thorpe H, Walker J, Jayne DG, et al. (2005) Shortterm endpoints of conventional versus laparoscopic-assisted surgery in patients with colorectal cancer (MRC CLASICC trial): multicentre, randomised controlled trial. Lancet 365: 1718-1726.

45 Arezzo A, Passera R, Salvai A, Arolfo S, Allaix ME, et al. (2015) Laparoscopy for rectal cancer is oncologically adequate: a systematic review and meta-analysis of the literature. Surg Endosc 29: 334-348.

46 Velthuis S, Veltcamp, Helbach M, Tuynman JB, Le TN, et al. (2015) Intra-abdominal bacterial contamination in TAMIS total mesorectal excision for rectal carcinoma: a prospective study. Surg Endosc 29: 3319-3323.

47 Chen CC, Lai YL, Jiang JK, Chu CH, Huang IP, et al. (2016) Transanal Total Mesorectal Excision Versus Laparoscopic Surgery for Rectal Cancer Receiving Neoadjuvant Chemoradiation: A Matched CaseControl Study. Ann Surg Oncol 23: 1169-1176.

48 Ma B, Gao P, Song Y, Zhang C, Zhang C, et al. (2016) Transanal total mesorectal excision (taTME) for rectal cancer: a systematic review and meta-analysis of oncological and perioperative outcomes compared with laparoscopic total mesorectal excision. BMC Cancer 16: 380 . 